\title{
O JOGO DIDÁTICO COMO RECURSO MOTIVADOR E FACILITADOR DA APRENDIZAGEM
}

\section{THE DIDACTIC GAME AS A MOTIVATIONAL RESOURCE AND A LEARNING FACILITATOR}

Estér Beatriz Mendes do Nascimento ${ }^{1}$; Anna Karollyne Ferreira de Lima ${ }^{2}$; Sanderson Hudson da Silva Malta ${ }^{3}$

\section{INTRODUÇÃO}

O ensino ao longo dos anos mudou, com base nas necessidades sociais emergentes, foi-se o tempo, por exemplo, que a comunidade escolar baseava o fracasso dos alunos como culpa deles mesmos, por não conseguirem aprender e que o recurso didático empregado pelo professor era apenas a exposição oral do conteúdo. Cabe frisar que Cunha (2012) afirma que parte desse fenômeno está atrelado ao trabalho do professor e continua dizendo que: "a ideia do ensino despertado pelo interesse do estudante passou a ser um desafio à competência do docente. $\mathrm{O}$ interesse daquele que aprende passou a ser a força motora do processo de aprendizagem, e o professor, o gerador de situações estimuladoras para aprendizagem." (CUNHA, 2012, p. 92).

Nesse sentido é preciso que os professores busquem recursos alternativos para facilitar a aprendizagem e o jogo didático é um desses recursos alternativos. Segundo Soares (2016) que traz o conceito de jogo didático sob o embasamento de vários teóricos como uma atividade lúdica, que tem regras explícitas e implícitas, que é também caracterizado como por meio de um material concreto/objeto, que muitas vezes é o instrumento do jogo e que tem a finalidade, de maneira muito desafiante, pois atrela o lúdico e os conhecimentos sistematizados, de possibilitar o acesso ao conhecimento.

Portanto, com base nos fatos anteriormente descritos e com o arcabouço teórico que norteia a produção e execução de um jogo didático, o objetivo desse relato é mostrar a vivência da aplicação de um jogo didático, demonstrando que ele é um recurso viável para a revisão e avaliação do conteúdo de Funções Orgânicas numa turma de terceiro ano do ensino médio.

\footnotetext{
${ }^{1}$ Licenciatura Plena em Química, Instituto Federal de Educação, Ciência e tecnologia de Pernambuco- IFPE, esterb654@gmail.com

${ }^{2}$ Licenciatura Plena em Química, Instituto Federal de Educação, Ciência e tecnologia de Pernambuco- IFPE, annakarollyne95@gmail.com

${ }_{3}^{3}$ Especialista, Instituto Federal de Educação, Ciência e tecnologia de Pernambuco- IFPE, sanderson.malta@vitoria.ifpe.edu.br
} 


\section{RELATO DE EXPERIÊNCIA}

A prática interventiva foi realizada na Escola Técnica Estadual José Joaquim da Silva Filho, no município de Vitória de Santo Antão em Pernambuco, em uma única turma de terceiro ano do ensino médio. Foi utilizado um jogo como recurso didático em que os 42 alunos da turma foram divididos em dois grupos e desses dois dez alunos de cada grupo se voluntariaram para fazer parte da dinâmica, e os outros ficaram como auxiliadores dos voluntários no processo do jogo.

Nesse jogo eram mostradas imagens de compostos químicos, que eles teriam que identificar as funções orgânicas pertinentes ao composto em questão, ou realizar o desafio de escrever o nome ou desenhar o composto primeiro ou responder a questões sobre a aplicabilidade da química orgânica na sociedade. Quando um integrante do grupo respondia certo, ele saia e dava lugar ao próximo da fila e em cada pergunta eles tinham um determinado tempo para responder, caso não respondesse ou a resposta estivesse errada perdia o ponto e o integrante permanecia, quem conseguisse ficar com a menor quantidade de integrantes na fila ao término das perguntas ganhava. Porém ele poderia pedir a ajuda de integrantes fora da fila para ajudar nas respostas.

Antes da aplicação da prática a turma foi observada e foi percebido, já considerando uma análise fenomenológica, que muitos alunos estavam desmotivados e não conseguiam identificar a presença e importância da química orgânica em suas vidas e para a sociedade. De forma que muitos consideravam essa área sem importância para suas vidas, ou que a profissão que eles tinham escolhido não tinha haver com a química orgânica. Por isso as perguntas e as atividades que norteavam o jogo eram todas contextualizadas com a aplicação da química na sociedade e sobretudo foi mostrado o envolvimento da mesma em muitas profissões.

Depois da prática, quando foi perguntado aos alunos a importância que ela teve para as suas vidas e formação, mais de $60 \%$ disseram que foi importante pois os fez enxergar a química nos âmbitos fora do papel, da teoria, que "foi boa para aprender mais". E com relação a esse recurso como função avaliativa, em muitas perguntas foi observado que os dois grupos erraram e que isso se deve a dificuldades em comum que a turma apresenta. Contudo em outras perguntas dois acertaram e ao longo da atividade quando as dúvidas ou erros foram levantados o professor foi trabalhando de forma que paulatinamente elas foram sendo sanadas, pois é necessário que o professor saiba levar o aluno a saber e fazer além do que ele já sabe, de forma que "a pedagogia deve orientar-se não no ontem, mas no amanhã do desenvolvimento da criança" (VIGOTSKI, 2009, p. 333).

Segundo Messender e Moradillo (2016) o jogo tem um papel de auxiliar o professor 
para alcançar um desenvolvimento no aluno, ele deve ser pensado de forma a auxiliar na apropriação do conhecimento científico. Portanto nele devem estar contidas as intencionalidades do processo educativo e deve ser fundamentado com conteúdos científicos atrelados ao mesmo.

Figura 1: Momento do Jogo, primeiro grupo. Fonte: Própria

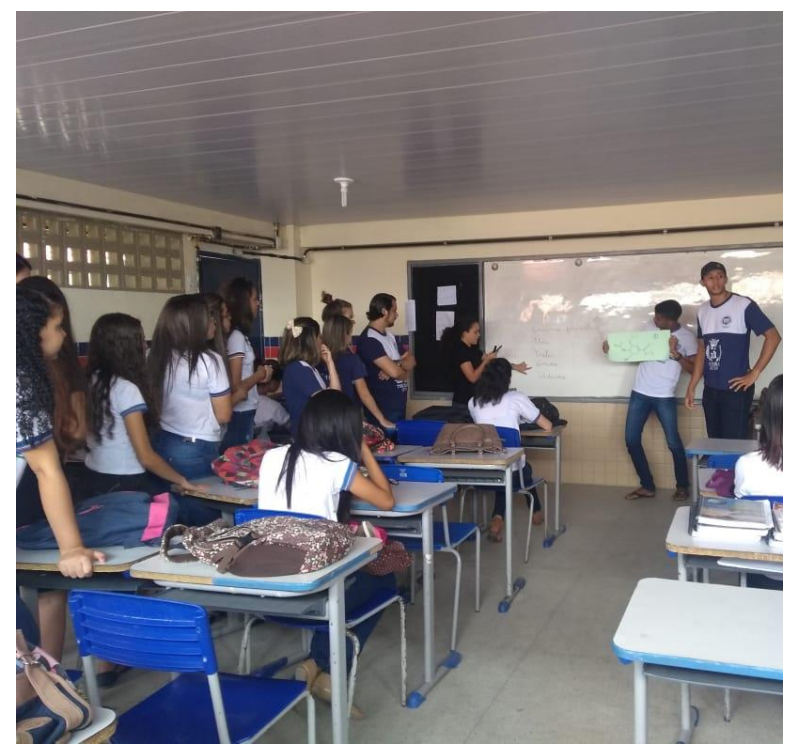

Figura 2: Momento do jogo, segundo grupo. Fonte: Própria.

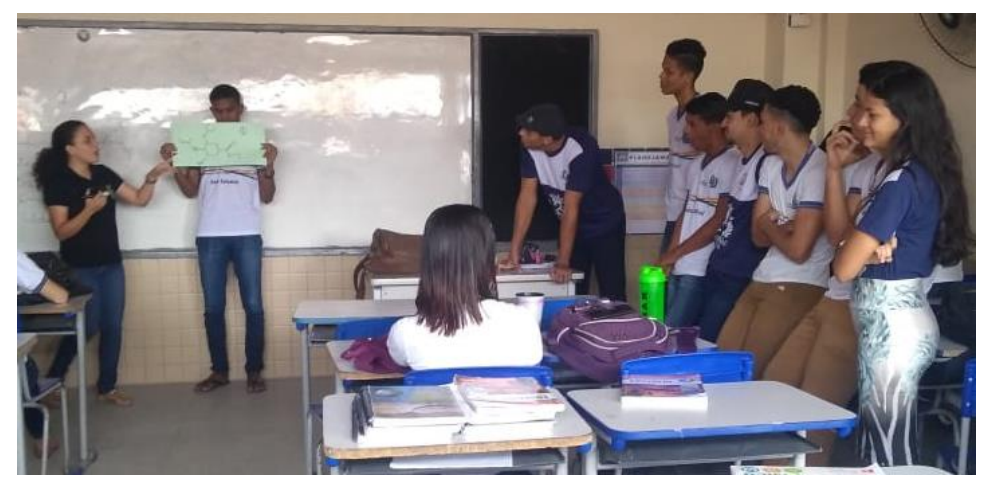

\section{CONSIDERAÇÕES}

A atividade realizada, como os próprios discentes trouxeram, foi de grande importância para que eles pudessem enxergar a química orgânica "com outros olhos". Como instrumento de avaliação ela também obteve êxito pois possibilitou a sondagem do que os alunos sabiam ou não sabiam a respeito do conteúdo anteriormente vivenciado. E posteriormente nas discussões sobre a aplicabilidade da mesma ela ainda teve um papel de ampliadora dos conceitos.

Portanto ao trabalhar com uma turma desmotivada e sem perspectiva o jogo possibilitou a superação dessas dificuldades, além de ter sido uma alternativa viável para a 
revisão e avaliação dos alunos.

\section{REFERÊNCIAS}

CUNHA, M. B. Jogos no Ensino de Química: Considerações Teóricas para sua Utilização em Sala de Aula. Química Nova na Escola, v. 34, n. 2, p. 92-98, 2012;

MESSEDER NETO, H. S.; MORADILlO, E. F. O Lúdico no Ensino de Química: Considerações a partir da Psicologia Histórico-Cultural. Química Nova na Escola, v. 38, n. 4, p. 360-368, 2016.

SOARES, M. H. F. B. Jogos e Atividades Lúdicas no Ensino de Química: Uma Discussão Teórica Necessária para Novos Avanços. Revista Debates em Ensino de Química, v. 2, n. 2, p. 5-13, 2016;

VIGOTSKI, L. S. A construção do pensamento e da linguagem. Tradução de Paulo Bezerra. São Paulo: Martins Fontes, 2009b. 